\title{
ARISTOTLE'S MIRROR: COMBINING DIGITAL AND MATERIAL CULTURE
}

\author{
C. Rossi ${ }^{1}$ \\ ${ }^{1}$ Politecnico di Milano, Department ABC, Via Ponzio 31 Milano, Italia - corinna.rossi@polimi.it
}

Commission II, WG II/8

KEY WORDS: digital culture, material culture, archaeological restoration, valorisation, Saqqara, New Kingdom tombs

\begin{abstract}
:
This article focuses on the relationship between digital and material culture, and on the necessity to establish a dialogue between them centred on the needs of the latter, rather than led by the potential of the former. Our understanding of the material culture changes continuously, and the advent of the digital era represents a significant opportunity to improve and increase our knowledge. The application of modern technologies can only be implemented thanks to a strict collaboration between experts of digital and material culture, as the two points of view can offer fresh insights to one another. It is important to stress, however, that the application of modern technologies should be implemented in order to answer specific research questions, inspired by a precise underlying philosophy, and not simply by which technology is currently available and applicable.
\end{abstract}

\section{INTRODUCTION}

Digital culture is spreading fast in the realm of cultural heritage. The use of lasers, drones and photogrammetry to acquire survey data and construct three-dimensional models is becoming the rule, rather then the exception; scientific and popular dissemination heavily relies on the results of these operations, that find further applications in the fields of virtual and augmented reality.

The number of possible applications is growing exponentially, also fuelled by the rapidity that characterises the technological development. Technology moves independently: it follows and shapes, at the same time, the expectations of the wider public, that represents its market. Once a specific action or result becomes possible, it finds its way into the surrounding world, including the vast field of cultural heritage.

Rather than simply following the tide and passively accept what the new technologies can offer, specialists in the humanities are called to make the effort to foresee possible innovative applications, not in terms of technological development, but rather in terms of new forms of valorisation and new research questions that can now be imagined. This paper, written from an Egyptological point of view, aims at encouraging a discussion on the proactive role that, in general, the humanistic disciplines should take in order to shape the future study of the material culture, at this crucial moment in which the digital culture is starting to offer a wealth of innovative tools (Greco, 2019).

\section{EXPLOITING THE POTENTIAL}

The contribution of modern technologies is fundamental to our understanding of the past; there is no doubt concerning this basic assumption. Focussing on the realm of archaeology, however, in many cases archaeological projects and museums appear to follow a way designed and paved by others, rather than to take the lead.

This is particularly visible in the adoption of digital imaging: a large number of museums and archaeologists nowadays adopt three-dimensional surveys and construct digital models, but they use them as they would (and did, until now) use photographs, as visualisation tools. In many cases, therefore, new tools are used to perform old operations, which may 'look better', but that do not necessarily correspond to a real improvement in terms of substance. A conscious, active and proactive use of digital imaging and new technologies in the field of cultural heritage would greatly benefit from a discussion a priori, led by specialists in humanities, who can indicate for which purpose the material culture should be interrogated. Clearly, testing new technologies on the cultural heritage can produce, a posteriori, interesting and unexpected results, but this cannot be the only direction of interaction between digital and material culture. The risk of not engaging in a preliminary discussion is to end up performing technically innovative operations only for the sake of the digital aspect, and miss the opportunity to answer precise research questions based on the physical objects. For instance, the web is being rapidly populated by three-dimensional models of items and buildings, without any particular attention to their fundamental characteristics (precision, accuracy, scale, etc.). There is a huge gap between a basic three-dimensional model based on a dozen photographs and a detailed model created from a submillimetric survey, either by photogrammetry or scanner, that makes, in turn, a huge difference in terms of these models can be later used. The choice of the type and resolution of the survey to be performed should be made on the basis of the reasons why the ensuing model is expected to be used, and should therefore be taken by the archaeologists or museum curators, obviously in collaboration with the surveyors. It is therefore necessary is to encourage a dialogue between the specialists in humanities and the specialists in digital imaging, in order to find the most productive technical solution to be applied to every specific research question. The final aim should be to obtain not necessarily the most innovative product, but the most productive way to answer the research questions that have been posed on a specific object, that is being studied in a given moment and under given circumstances. Once a digital model has been created, it can be used for a number of purposes, both in the realm of dissemination (at a popular and at a scientific level) and in that of research. If the latter is still in its infancy, the former is quickly gaining pace and space: three-dimensional models are widely used not only to illustrate shape and appearance of items ranging from small objects to large buildings, but also exploited to create immersive experiences based on virtual tours and augmented/mixed reality. 
A possible application of this virtual enhancement of the reality is the opportunity to do in the virtual realm what cannot be done in the real world: in primis, re-unite elements that have been separated and reconstruct the lost contexts.

In general, an archaeological excavation is a destructive activity: progressively, archaeologists physically remove the layers that accumulated over the centuries, and separate forever the items that are found during the excavation from their original context. When the components of the stratigraphy are divided, some items start a new life, becoming objects to be studied and to be placed on display (Greco, 2018). If nowadays the tendency to leave the items retrieved from an archaeological site in its proximity prevails, in the past it was not so: the majority of the large European museums exhibit items transferred there from foreign countries in periods in which the law allowed to do so. In particular, the most important Egyptian collections held in European museum were created under these circumstances (e.g. Stevenson, 2019).

Over the time, as the sensibility over the relationship between host and foreign countries changed, there have been several cases of disputes over the past actions; one of the most famous, is the discussion over the bust of Nefertiti, found in 1912 by a German mission and transported to Berlin according to the partage (the law allowing the division of finds), a circumstance that was later regretted by the Egyptian authorities (Merryman et al., 2007, 414-418).

Apart from a number of high-profile controversies over famous objects, being separated from their original context was the fate of most of the items that populate museums (Greco, 2018), and re-uniting these disjecta membra can be a complex task both for practical and technical reasons (Greco, 2011). However, the virtual realm can offer a significant contribution, for instance by re-uniting items originally belonging to the same group, and recomposing items on display in museums with their original finding place (e.g. Gottarelli, 1986; Betrò, 2011).

\section{VIRTUAL EXPANSIONS}

Apart from re-combining objects and places, the virtual realm can also help to achieve what cannot be achieved in reality also on buildings or entire archaeological sites, when political, physical, logistic or environmental conditions dictate their conditions.

An interesting case for discussion is represented by the group of New Kingdom tombs of Saqqara located near the pyramid of Unas, south of the Step Pyramid of Djoser (figure 1). Differently from their contemporary counterparts built on the West Bank of Thebes (modern Luxor), which were mainly rockcut, these were built-up structures resembling small temples, and are for this reason called 'temple-tombs' (Snape, 2011, 217-222).

Figure 1. Panoramic view of the area of the New Kingdom tombs of Saqqara, located to the south of the pyramids of

Djoser and Unas (photograph by L. Perfetti, 2019).
They date to the period of the Eighteenth and Nineteenth Dynasty, and include the tombs of Maya, Treasurer of Tutankhamun (Martin et al. 2012) and of Horemheb, who built this tomb for himself when he was a general of the Egyptian army (Martin, 1989); he later became pharaoh and was eventually buried in a rock-cut tomb in the Valley of the Kings, on Thebe's West Bank (Reeves, Wilkinson, 1996, 130-133).

The existence at Saqqara of the tombs of a number of New Kingdom high officials was known, as these monuments had been pillaged in the late Nineteenth Century and the finds scattered over several European museums. Starting from the mid-' $70 \mathrm{~s}$, the systematic exploration of the area led to the discovery, one after the other, of the majority of them (Martin, 1991; 1997; 2001; Raven, 1991; 2005; Raven, van Walsem, 2014).

These temple-tombs were mainly built of mudbricks, and consisted of a linear sequence of open-air courtyards, sometimes surrounded by columnades, that terminated into three cult chapels (figure 2). Some of them were endowed with a pylon at the entrance. The lower courses of the walls were lined by decorated orthostats; a shaft, located in one of the courtyards, led to the subterranean portion of the tomb, that hosted the deceased and his family members.

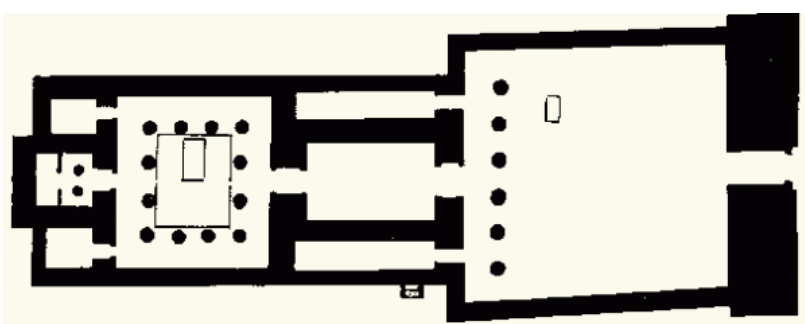

Figure 2. Plan of the temple-tomb of Maya (from www.saqqara.nl/tombs/tomb-of-maya-found-in-1986/)

The superstructures heavily suffered the passing of time, not only because of the fragility of mudbricks, but also because they were dismantled to provide convenient building material during the subsequent occupation of the area. The substructures consist of earlier funerary pits and corridors dating to the Archaic Period and to the Old Kingdom, that were later modified and reused more than once. The presence of some architectural features suggest that, for instance, part of the subterranean spaces of the tomb of Meryneith might originally belong to the tomb of a high-ranking officer or even to a member of the royal family of the Archaic Period (Beex, Raven, 2014).

Once unearthed (figure 3), this type of remains requests immediate action to be preserved: mudbricks decay very quickly under the combined action of erosion and insects that attack the mudbrick temper, whilst the decorated orthostats are rapidly damaged by the sand-laden wind; the strong sunlight bleaches the surviving colours and, in general, humidity and variations of temperature affect all types of remains.

For all these reason, and to make the site as whole accessible to

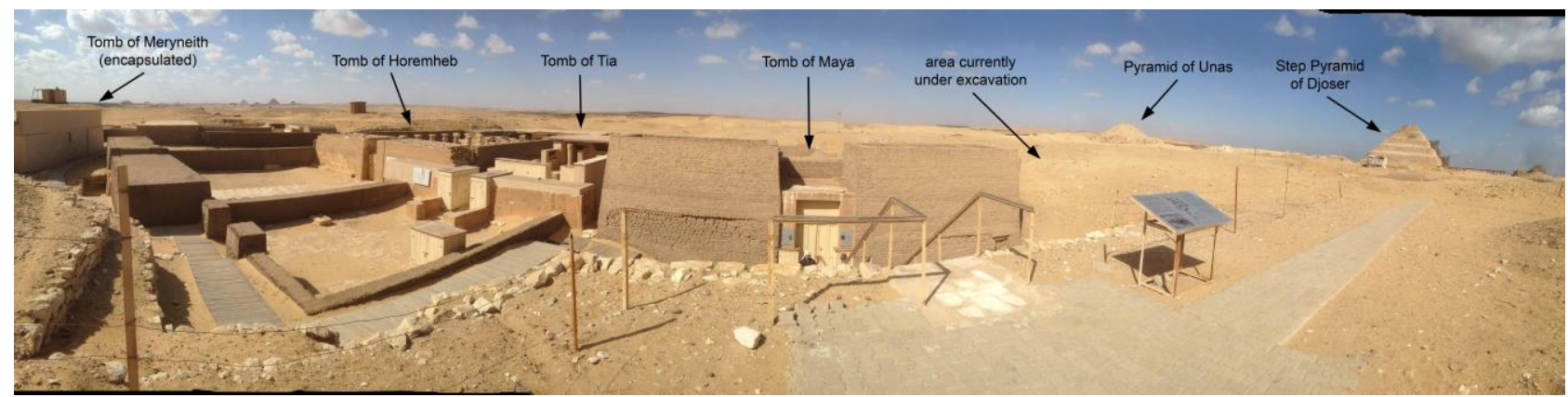


tourists, over the years all the excavated tombs have been the subject of significant interventions, including substantial reconstruction of missing parts and addition of protective structures (Warner, 2009).

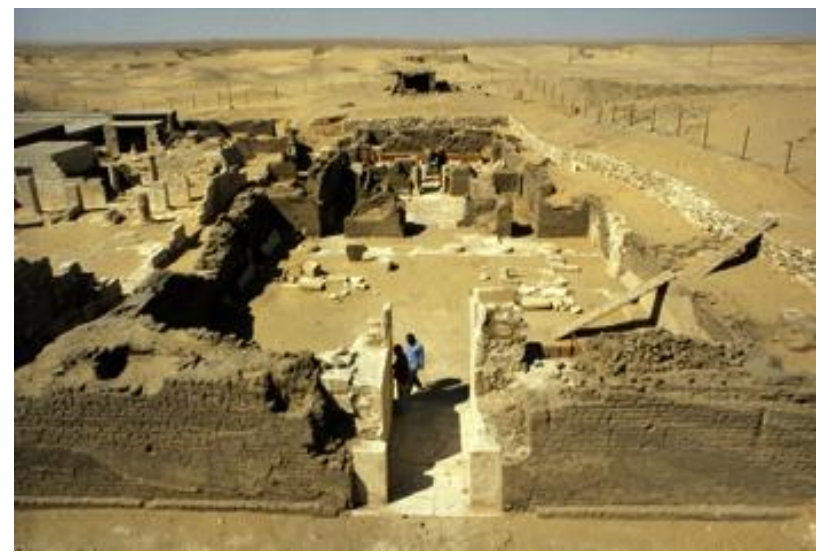

Figure 3. The Tomb of Maya when it was unearthed (from www.saqqara.nl/tombs/tomb-of-maya-found-in-1986/)

Two types of interventions have been carried out: major reconstructions and addition of protective structures. The first type, applied to the majority of tombs, saw the addition of new mudbrick masonry over the original remains, and the construction of roofs and shelters to protect the architectural remains. Naturally ventilated wooden lockers were built all along the decorated orthostats; they can be opened by visitors to look inside, and then closed again. This is the system applied to protect the tombs of Maya, Tia and Tia, Ptahemwia, Pay and Raia and partly also Horemheb. The current aspect of the tombs of Maya and Horemheb can be directly seen on the web thanks to two 3D virtual tours offered by the Friends of Saqqara. ${ }^{1}$

The second type of intervention has been applied only to the relatively small tombs of Meryneith (figure 4), high-ranking official who lived under the pharaohs Akhenaten and Tutankhamun. Differently from the others, this one was left more or less as it was found when it was unearthed: the protection is entrusted to a masonry coffer that encapsulates the entire tomb (Warner, 2009, 111-112).

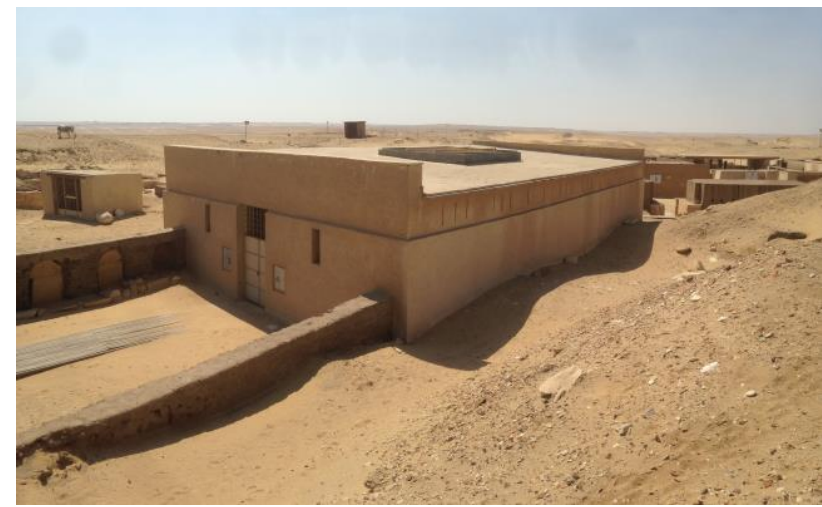

Figure 4. The tomb of Meryneith, encapsulated in a protective structure (photograph by L. Perfetti, 2019)

Both types of interventions have been carefully considered: taking into account the logistic and environmental conditions,

\footnotetext{
${ }^{1}$ www.saqqara.nl/tombs/virtual-tour-maya/ and www.saqqara.nl/tombs/virtual-tour-horemheb/.
}

the chosen solutions represent the best possible practical method to protect the architectural and artistic remains. There are prices to pay, though, and clearly the intelligibility of the tombs at first sight has been somehow lost in the process (figure 5). Currently, only visitors with a previous knowledge of the historical and architectural background of these tombs are able to 'see through' these protective structures, that otherwise tend to take most of the visual scene.

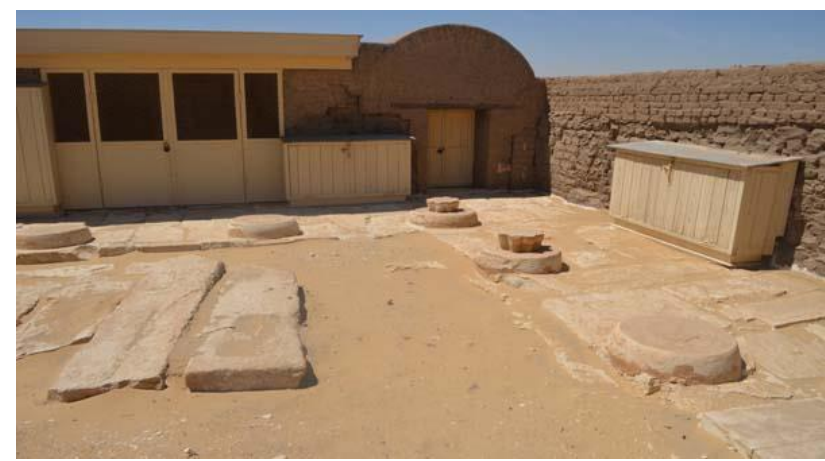

Figure 5. The Tomb of Pay and Raia after the restoration works

(from www.sharm-club.com/egypt/ancient-tombs/pay-raiatomb-saqqara-necropolis).

The elaboration of the 3D surveys of the tombs of Maya and Tia offered an occasion to reflect on this issue. These surveys were performed in 2018 by the 3D Survey Group, Politecnico di Milano, for the Dutch-Italian mission currently working at these tombs, led by Museo Egizio, Torino and Rijksmuseum van Oudheden, Leiden. Turning the survey data into 3D models was generously funded by the Friends of Saqqara, and represented an occasion to reflect on the possibility to present the data in a different way.

The virtual realm certainly allows to proceed with modifications to the digital model that could never find a correspondence in the reality, for a number of different reasons. This possibility must be handled with care, as significant modifications to the 3D model would detach from the reality, and would make it unusable for research purposes.

The first, immediate idea was to digitally remove the wooden lockers in order to make the orthostats visible. Of course, it would be in theory possible to remove them completely; this operation, however, would create large gaps in the survey data, and impose a significant reconstruction of the lower portions of the tombs. It would be a virtual reconstruction, but always a reconstruction, subject to exactly the same problems of a real one, which would therefore imply more or less arbitrary decisions on the dimensions of the missing parts, the necessity to deal with the temptation to fill the gaps just for the sake of it, and so on.

The purpose of these 3D survey and models was to document the current state of the tombs and offer a tool for further studies. Therefore, the decision was taken to keep the modifications to a minimum. In this way, the model can be still used, for instance, to take measurements and study alignments. However, the chance to make some non-committal modifications in order to enhance the perception of the archaeological remains was indeed exploited: the team opted for the digital removal of the doors of the wooden lockers, so that it is possible to directly see the orthostats inside (figures 6 and 7). The flat roofs made of steel and wood that cover portions of the tombs were also digitally removed, but not the reconstructed portions of the mudbricks walls that support them. 


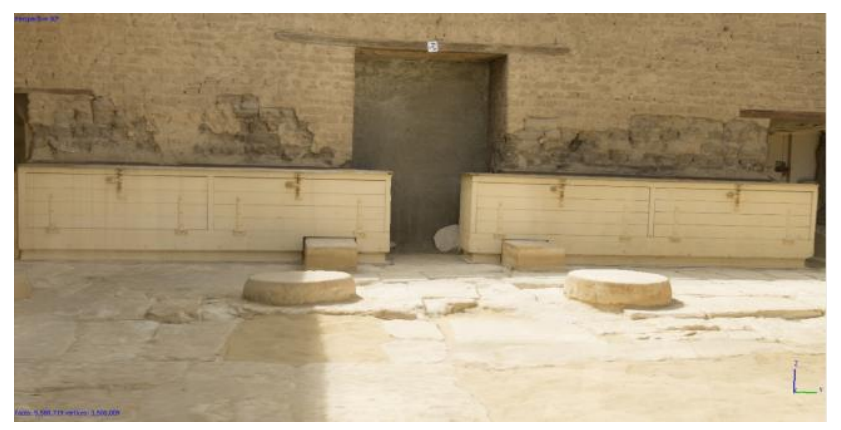

Figure 6. View of the 3D model of the tomb of Maya showing the wooden lockers located in the second courtyard, as surveyed (elaboration by F Fiorillo, 2018).

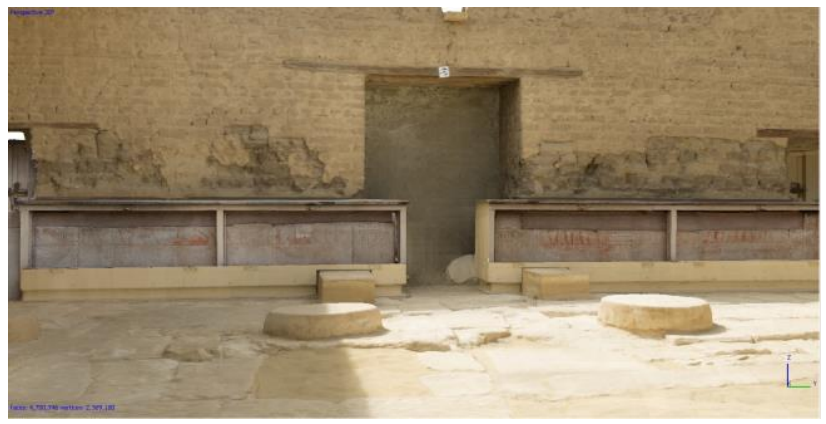

Figure 7. Same view of the 3D model of the tomb of Maya after the digital removal of the wooden lockers

(elaboration by F. Fiorillo, 2018).

The 3D surveys and the ensuing models can inspire further considerations. This is, in fact, an ideal case to discuss the possibility to let the virtual realm into the picture, with the task of accompanying the reality. It is not a matter of refusing the reality and 'photoshopping' it to make it look different, but rather of complementing it by revealing what is hidden, and adding what is lost.

A project of virtual valorisation of these tombs might allow visitors to acquire a wealth of information that is currently invisible, either because covered or because lost: the tombs of Maya, Tia, Ptahemwia and Meryneith could be virtually freed from their protective shells, seen under the sunlight as they were first seen by the excavators, even reconstructed as they were at the time they were actually built; the dispersed orthostats could virtually return to the tomb of Horemheb, and be seen once more all together.

All this information could be presented in a multisensorial installation, enriched by the addition of textual and iconographic contents, to be placed in the local museum and to be visited before the archaeological remains. It is important again to highlight that this operation would run in parallel with the physical visit to the site: its purpose would be to complement it, not to substitute it.

An interesting addition, to be evaluated, would be the adoption, during the visit to the archaeological remains, of oculi able to offer an alternative, virtual view of the surroundings, thus materializing the complementarity of the digital and the material worlds.

\section{ARISTOTLE'S MIRROR}

A promising direction of research would therefore be to carefully avoid a conflictive relationship between digital and material culture, based on the attempt either of the former to substitute the latter, or of the latter to diminish the role of the former. The collaboration between digital and material culture should recall what Aristotle wrote about friendship: 'and so, just as when we want to see our own faces, we see them by looking in a mirror, similarly when we wish to know our own character, we can know them by looking up a friend. For a friend, as we say, is another self' (Arist. MM 1212b8-24; translation from Barnes, 1984). Digital and material culture should therefore act as character-friends, 'distinct yet complementary' (Sherman, 1989, 141): 'because the friend can be observed with greater objectivity than the self, knowledge of the friend's character and "intuitively felt" knowledge of one's similarity to the friend serve as a "bridge" to self-knowledge. In this way, self-knowledge mediated through friendship provides protection against self-deception' (Biss, 2011, 131; Cooper, 1998, 281-284).

Each counterpart, both the digital and the material culture, can stand by themselves, and yet it is only their combination that can reveal aspects, details and characteristics that would otherwise either be invisible or go unnoticed. Thanks to this collaboration, it will be possible to face one the most meaningful and important challenges of modern archaeology and museology: the re-contextualisation of finds, ranging from objects to entire buildings (Greco, 2018).

\section{CONCLUSIONS}

Asking questions before we act is always important, at all levels, as the direction of the following actions depends on the initial question. In the realm of archaeology, in order to be really productive, the questions should be centred on and take inspiration from the material culture, rather than let some answers appear from the casual application of the currently available technologies. It is not my intention to dismiss the value of bold attempts combining elements in an unexpected way, which might, or might not, produce equally unexpected results. What I aim at underlying is the necessity that the research questions on the material culture should come, first of all, from experts in humanities, including archaeologists, museum curators, and historians. The direction which we wish to take when we interrogate the material culture should be established, first of all, at a philosophical level; then it can be shared with experts in the fields of technology, who are likely to greatly contribute by proposing new technical solutions.

\section{ACKNOWLEDGEMENTS}

Thanks to Dr. Christian Greco (Museo Egizio, Torino) for many fruitful discussions on this complex subject, and to Prof. Stefano Della Torre (Department ABC, Politecnico di Milano) for his constant encouragement to explore new directions of research. Thanks to the Dutch-Italian Mission to Saqqara for sharing data and information, and to the Friends of Saqqara for funding the elaboration of the models. Thanks also to Cinzia Tommasi for her suggestions and comments on the final version of this paper. This article is the result of the research carried out by the project L.I.F.E., funded by the European Research Council (ERC) under the European Union's Horizon 2020 research and innovation programme (grant agreement 681673). 


\section{REFERENCES}

Barnes, J. (ed.), 1984. Complete Work of Aristotle, Revised Oxford Translation. Princeton University Press, Princeton, NJ.

Beex, W. F. M., Raaven, M. J. (2014). The Architecture. In M. J. Raven, R. van Walsem, The Tomb of Meryneith at Saqqara. PALMA 10. Brepols, Turnhout.

Betrò, M. 2011. Virtual environments and web community in archaeology: Theban Tomb 14 as case study. In Belova G. A. (ed.), Achievements and Problems of Modern Egyptology, Proceedings of the International Conference held in Moscow on September 29-October 2, 2009. Russian Academy of Sciences, Center for Egyptological Studies, 38-46.

Biss, M., 2011. Aristotle on friendship and self-knowledge: the friend beyond the mirror. History of Philosophy Quarterly, $28(2), 125-140$

Cooper, J. M., 1998. Friendship and the Good in Aristotle. In N. Sherman (ed.), Artistotle's Ethics: Critical Essays. Rowman \& Littlefield Publishers, Inc., Lanham, MD: 277-300.

Gottarelli, A., 1986. Museografia e informatica: la ricostruzione virtuale della tomba Menfita del generale Horemheb. Archeologia e Calcolatori 7, 1091-1099.

Greco, C., 2011. The lost tomb of Ptahmes, in Buzi, P., Picchi, D., and Zecchi, M. (eds.). Aegyptiaca et Coptica, Studi in onore di Sergio Pernigotti. BAR International Series 2264. Hadrian Books, Oxford, 195-199.

Greco, C., 2018. Il museo e la sua natura. In AAVV, Anche le statue muoiono: conflitto e patrimonio tra antico $e$ contemporaneo (catalogue of the exhibition Statues also die at Museo Egizio, Fondazione Sandretto Re Rebaudengo, Musei Reali Torino), Modena, Panini, 21-27.

Greco, C., 2019. La biografia degli oggetti. Rivoluzione digitale e Umanesimo. in AAVV, Archeologia Invisibile (catalogue of the exhibition Invisible Archaeology, Museo Egizio, Torino, 12 March 2019 - 6 January 2020), Modena, Panini, 14-20.

Martin, G. T., 1989. The Memphite tomb of Horemheb, commander-in-chief of Tut'ankhamūn, I: the reliefs, inscriptions, and commentary. London, Egypt Exploration Society.
Martin, G. T., 1991. The Hidden Tombs of Memphis. London, Egypt Exploration Society.

Martin, G. T., 1997. The Tomb of Tia and Tia, a Royal Monument of the Ramesside Period in the Memphite Necropolis. London, Egypt Exploration Society.

Martin, G. T., 2001. The Tombs of Three Memphite Officials. Ramose, Khay and Pabes. London, Egypt Exploration Society.

Martin, G. T., Van Dijk, J., Frazer, K. J. 2012. The Tomb of Maya and Meryt, I: The reliefs, Inscriptions, and Commentary. London, Egypt Exploration Society.

Merryman, J. H., Elsen, A. E., Urice, S. K., 2007. Law, Ethics, and the Visual Arts. Kluwer Law International, Alphen aan der Rijn.

Raven, M. J., 1991. The Tomb of Iuredef. A Memphite Official in the Reign of Ramesses II. London and Leiden, Egypt Exploration Society and National Museum of Antiquities Leiden.

Raven, M. J. 2005. The Tomb of Pay and Raia at Saqqara. London and Leiden, Egypt Exploration Society and National Museum of Antiquities Leiden.

Raven, M. J., van Walsem, R., 2014. The Tomb of Meryneith at Saqqara. PALMA 10. Brepols, Turnhout.

Reeves, N., Wilkinson, R., 1996. The Complete Valley of the Kings. Thames and Hudson, London.

Sherman, N., 1989. The Fabric of Character. Clarendon Press, Oxford.

Snape, S., 2011. Ancient Egyptian Tombs. The Culture of Life and Death. Wiley-Blackwell, Malden and Chichester.

Stevenson, A., 2019. Scattered Finds. Archaeology, Egyptology and Museums. UCL Press, London.

Warner, N. 2009. Protecting a Cemetery in Saqqara: Site Works 1975-2009. Conservation and mgmt of arch. sites, 11(2), 98132. 